\title{
Risperidone mucoadhesive buccal tablets: formulation design, optimization and evaluation
}

This article was published in the following Dove Press journal:

Drug Design, Development and Therapy

Number of times this article has been viewed

\section{Burak Çelik}

Department of Pharmaceutical Technology, Faculty of Pharmacy, Bezmialem Vakıf University, Fatih, Istanbul, Turkey
Correspondence: Burak Çelik

Adnan Menderes Bulvarı, Bezmialem Vakıf University, Fatih, 34093 Istanbul, Turkey

Tel +902125232288

Fax +90 2124531870

Email eczburakcelik@gmail.com
Abstract: The aim of this study was to design and optimize risperidone (RIS) mucoadhesive buccal tablets for systemic delivery as an alternative route. Direct compression method was used for the preparation of buccal tablets, and screening studies were conducted with different polymers to determine their effects on tablet characteristics. Carbopol ${ }^{\mathbb{B}}(\mathrm{CP})$ and sodium alginate (SA) were selected as two polymer types for further optimization studies by applying response surface methodology. Tablet hardness (TH), ex vivo residence time (RT), and peak detachment force (DF) from buccal mucosa were selected as three important responses. Physicochemical compatibility of formulation excipients and RIS was evaluated by using Fourier transform infrared (FT-IR) spectroscopy and differential scanning calorimetry (DSC) analysis. In vitro drug release profiles and release kinetics were investigated; swelling index and matrix erosion studies were conducted. Optimum formulation consisted of $16.4 \%$ CP and $20.3 \%$ SA, which provided 7.67 \pm 0.29 hour ex vivo RT, $45.52 \pm 4.85 \mathrm{~N}$ TH, and $2.12 \pm 0.17 \mathrm{~N}$ DF. FT-IR spectroscopy and DSC analysis revealed that there was no chemical interaction present between tablet ingredients. Cumulative RIS release of $>90 \%$ was achieved after 8 hours of in vitro dissolution studies, which was supported by swelling and matrix erosion analysis. Mechanism of RIS release was fitted best to zero-order model, while release exponent (n) value of 0.77 demonstrated an anomalous (non-Fickian) release, indicating combined erosion and swelling mechanism. The results suggested that optimized buccal tablets of RIS would be a promising and alternative delivery system for the treatment of schizophrenia.

Keywords: risperidone, Carbopol, sodium alginate, buccal tablets, mucoadhesion, quality by design, drug delivery, controlled release

\section{Introduction}

Risperidone (RIS) is a benzisoxazole derivative and atypical antipsychotic drug with high-affinity antagonism to $5-\mathrm{HT}_{2 \mathrm{~A}}$ serotonin and $\mathrm{D}_{2}$ dopamine receptors along with histamine, $\alpha_{1}$, and $\alpha_{2}$ adrenergic receptor blockade properties. RIS is primarily used in the treatment of schizophrenia and bipolar disorders as oral solution, conventional tablet, orally disintegrating tablet, and long-acting intramuscular injection. RIS is practically insoluble in water at neutral $\mathrm{pH}$ and considered as class II (high-permeability, low-solubility) drug according to Biopharmaceutical Classification System. ${ }^{1}$ RIS is rapidly absorbed after oral administration but undergoes significant first-pass metabolism. Along with differences in intestinal absorption, this causes variability in plasma concentrations. Patient compliance is also a major problem in antipsychotic treatment, especially with oral route. Intermittent treatment has an enhanced risk of relapse in these patients compared with continuous and stable treatment. Long-acting injection of RIS alleviates these problems to a certain extent, ${ }^{2}$ but the inability to stop treatment in the event of severe side effects raises the need of an alternative and noninvasive 
drug delivery. Intranasal ${ }^{3}$ and transdermal ${ }^{4}$ delivery routes have been investigated in recent years, and successful results were obtained by different research groups. Heemstra et al demonstrated that after application in a mucoadhesive gel formulation, RIS had sufficient permeability via passive diffusion through buccal mucosa to achieve therapeutically relevant plasma concentrations. ${ }^{5}$ Mouth dissolving films ${ }^{6}$ and buccal patches ${ }^{7}$ of RIS were also formulated and evaluated by different research groups, and significant advantages over conventional tablets were observed.

Buccal delivery is an alternative route of drug administration with several advantages over traditional oral route. Buccal mucosa is highly vascularized, and blood flow drains directly into jugular vein; therefore, drugs absorbed through the buccal mucosa bypass the gastrointestinal route and hepatic first-pass effect. Buccal cavity is easily accessible for patients, dosage forms can be easily applied, and drug delivery can be terminated in case of an emergency and unexpected side effect. ${ }^{8,9}$ Buccal drug delivery systems are investigated by different research groups as an alternative for systemic delivery, which can be prepared as tablets, discs, gels, patches, films, sponges, or wafers. There are different mucoadhesive dosage forms currently available in the market for local or systemic drug delivery. ${ }^{10}$ Buccal tablets can be formulated to retain their shape, integrity, and position during application time. They can be visually seen during treatment, and precise control of dosage can be achieved. Direct compression method can be used for the preparation of buccal tablets, which is easy-to-scale up, efficient, and economic method for large-scale production. ${ }^{11}$

Mucoadhesion is used to define the attachment of macromolecules to the mucosal membrane. After application to the oral cavity, dosage forms may become dislodged and swallowed accidently by the patients. This may cause interruptions or reduction in drug absorption during treatment. For this reason, it is important to provide sufficient mucoadhesion to retain the buccal tablet on the application site..$^{12,13}$ Various natural, semi-synthetic, or synthetic polymers are used in buccal formulations to achieve mucoadhesion. These polymers hydrate and swell with contact to mucus layer in the epithelium. Mucin, a specific component of mucus, is a high-molecular-weight glycoprotein with negative charge on the surface. ${ }^{14}$ Mucoadhesion strength varies based on the physicochemical properties of the polymer, characteristics of the biological material, and contact time of the dosage form. ${ }^{15,16}$

Conventional formulation design consists of changing a single variable each time, maintaining other factors constant.
However, this approach is time-consuming and requires a large number of trials to determine optimum conditions. Design of experiments (DoEs) is a statistical optimization method that can define the critical parameters with a minimum number of experiment series. ${ }^{17}$ Systematic evaluation of all variables at a time significantly accelerates the optimization process. Response surface methodology (RSM) is an efficient tool for formulation design and optimization purposes. This design method investigates the interaction between predetermined factors and their effects on desired responses that are critical to final formulation. ${ }^{18,19}$

The purpose of this study was to develop buccal tablet formulations of RIS for the first time to be used as an alternative delivery system in the treatment of schizophrenia. Screening studies were conducted with different polymers to determine their effects on powder flow and physical characteristics of buccal tablets, including mucoadhesive performances. I-optimal design was used with selected polymers for the purpose of formulation optimization. Swelling and erosion studies were conducted, and in vitro dissolution profile and drug release kinetics were investigated on optimized buccal tablet.

\section{Material and methods Materials}

RIS was kindly donated by ILKO Pharmaceuticals (Istanbul, Turkey). Carbomer (CP) Carbopol ${ }^{\circledR} 71 \mathrm{G}$ NF was kindly supported by Lubrizol (San Diego, CA, USA). Polyvinylpyrrolidone (PVP) Kollidon ${ }^{\circledR} 30$ was supplied by BASF (Ludwigshafen, Germany). Hydroxypropyl methylcellulose Methocel ${ }^{\mathrm{TM}} \mathrm{K} 4 \mathrm{M}$ was supplied by Colorcon (Dartford, Kent, UK). Acacia gum, chitosan (low molecular weight), guar gum (GG), hydroxyethyl cellulose (HEC), sodium alginate (SA), xanthan gum (XG), magnesium stearate, and Aerosil ${ }^{\circledR}$ 200 were purchased from Sigma-Aldrich, Inc. (St Louis, MO, USA). Lactose monohydrate (LM) Lactopress ${ }^{\circledR}$ spray-dried 250 was kindly gifted by DFE Pharma (Goch, Kleve, Germany). All other chemicals used in this study were of analytical grade, which were obtained from Merck (Darmstadt, Germany).

\section{Buccal tablet preparation}

Buccal tablets were prepared by direct compression method. Tablet ingredients were screened through a 0.150 -mm sieve before mixing to achieve a uniform particle size distribution. Then, $1 \mathrm{mg}$ of RIS and required amounts of polymer and LM were weighed carefully and mixed with a cubic mixer for 15 minutes. Magnesium stearate and Aerosil ${ }^{\circledR} 200$ were 
added to the powder mixture and blended for an additional 3 minutes. Buccal tablets were compressed by using a singlepunch tablet machine (TDP-5; Shanghai Tianfan Machinery Factory, Shanghai, China) equipped with $7-\mathrm{mm}$ round flat punch set. ${ }^{20}$ Tablet weight was kept constant at $100 \mathrm{mg}$, and the thickness of tablets was adjusted to $\sim 2 \mathrm{~mm}$. Tablets were stored in an airtight container away from the light for further studies.

\section{Physical characterization studies}

Before tablet compression, flow properties of powder mixtures were investigated. For bulk density determination, $10 \mathrm{~g}$ powder was precisely poured into a $50-\mathrm{mL}$ measuring cylinder without packing, and the powder volume was recorded. Tapped density was obtained by using a tapped density apparatus (Pharma Test PT-TD200, Hainburg, Germany) by tapping the powder 1,250 times, and resulting powder volume was measured. From the obtained powder density, Carr's index (CI) and Hausner ratio (HR) of powder mixtures were calculated using Equations 1 and 2:21,22

$$
\begin{gathered}
C I=\left(\mathrm{dt}-\frac{\mathrm{db}}{\mathrm{dt}}\right) \times 100 \\
H R=\frac{\mathrm{dt}}{\mathrm{db}}
\end{gathered}
$$

where $\mathrm{dt}$ and $\mathrm{db}$ are the tapped density and bulk density, respectively. Angle of repose (AR) values of powder mixtures were analyzed by using a powder flow analyzer (Pharma Test PTG S3). Briefly, powder mixture was poured inside the funnel and allowed to freely flow onto the fixed receptor pan. AR values of powder mixtures were obtained from the apparatus digitally.

After compression, the tablets were evaluated for weight variation, hardness, and friability (FB). ${ }^{23}$ Weight variation was measured on 10 randomly selected tablets using an analytical balance (Shimadzu AUW220D, Kyoto, Japan). Hardness of tablets was obtained by testing 10 samples using a hardness tester (Pharma Test PTB 111E). Tablet tensile strength (TS) was calculated from the previously obtained values using Equation 3:12

$$
\mathrm{TS}=\frac{2 \mathrm{~F}}{\pi \mathrm{dT}}
$$

where $\mathrm{F}$ is the tablet crushing force $(\mathrm{N})$, $\mathrm{d}$ is the tablet diameter $(\mathrm{mm})$, and $\mathrm{T}$ is the tablet thickness $(\mathrm{mm})$. FB testing was conducted on 20 tablets from each batch. Tablets were weighted and placed into the plastic drum of a friabilator (Pharma Test PTF 10E). Apparatus was rotated at $25 \mathrm{rpm}$ for 4 minutes, after which the excess dust was removed, and the tablets were reweighted for the calculation of FB (\%).

\section{Analytical quantification of RIS}

The analyses of RIS were performed by using a reversed-phase high-performance liquid chromatography (RP-HPLC) system (Shimadzu LC20-AT) equipped with an ultraviolet-visible detector (Shimadzu SPD-20A) at $280 \mathrm{~nm}$. The mobile phase was consisted of methanol/acetonitrile (70:30, v/v), which was filtered and degassed prior to use. Mobile phase was delivered at a flow rate of $0.8 \mathrm{~mL} / \mathrm{min}$ through a $\mathrm{C}_{18}$ column (InertSustain ${ }^{\circledR} ; 150 \times 4.6 \mathrm{~mm}, 5 \mu \mathrm{m}$; GL Sciences Inc., Tokyo, Japan) maintained at $30^{\circ} \mathrm{C} .{ }^{24,25} \mathrm{HPLC}$ method was validated based on International Conference of Harmonization Q2 (R1) guideline. Linearity was analyzed through standard curves in the range of $0.5-5 \mu \mathrm{g} / \mathrm{mL}$, prepared from stock solution of RIS. Regression equation was found as $\mathrm{y}=44,566 \mathrm{x}-1,927.9$ with a correlation coefficient $\left(\mathrm{R}^{2}\right)$ of 0.9992 . Intraday and interday precision expressed as relative standard deviation (RSD) and accuracy results expressed as relative mean error were found to be below $2 \%$ limit. Recovery results of RIS were found as $(98.52 \% \pm 0.85 \%)-(100.66 \% \pm 1.04 \%)$. Limit of detection and limit of quantitation values were calculated as 0.044 and $0.133 \mu \mathrm{g} / \mathrm{mL}$, respectively.

\section{Determination of drug content}

RIS content determination was performed on 10 randomly selected tablets. Briefly, tablets were crushed in a porcelain mortar, and $30 \mathrm{mg}$ of the powder was weighed and diluted suitably with methanol to $10 \mu \mathrm{g} / \mathrm{mL}$ theoretical concentration. After filtration through $0.45-\mu \mathrm{m}$ polytetrafluoroethylene filter, RIS content was analyzed by using RP-HPLC method validated previously.

\section{Determination of mucoadhesion strength}

Mucoadhesive strength of tablets was determined by using a texture analyzer (Middleboro, MA, USA). ${ }^{20,26}$ Fresh buccal mucosa from the sheep obtained from local slaughterhouse was used as a model membrane. Samples were prepared by separating the underlying adipose tissue, and the obtained mucosal membrane was cut into $2 \times 2 \mathrm{~cm}$ pieces. Tablets were attached with double-sided tape to the upper probe of the apparatus. Mucosa was fixed on the holder part and immersed partially in a $\mathrm{PBS}\left(\mathrm{pH} 6.6\right.$ ) medium at $37^{\circ} \mathrm{C} \pm 0.5^{\circ} \mathrm{C}$. Upper probe was lowered at a speed of $0.5 \mathrm{~mm} / \mathrm{s}$ until tablet contact 
with mucosa was achieved. Then, $1 \mathrm{~N}$ constant force was applied for 180 seconds to ensure enough wetting, and the probe was then withdrawn with a speed of $0.5 \mathrm{~mm} / \mathrm{s}$. Results were acquired as peak detachment force (DF), and the test was conducted in triplicate for each formulation.

\section{Determination of ex vivo residence time (RT)}

Ex vivo RT is an important parameter to ensure that buccal tablets remain on the site of application during the treatment. For this experiment, US Pharmacopeia (USP) disintegration tester (Pharma Test PTZ-S) was used with slight modification. ${ }^{27}$ The basket of the apparatus was removed, and the buccal mucosa that was fixed on a glass slide with cyanoacrylate glue was attached vertically. One side of the tablet was wetted and attached to the mucosal tissue with a small pressure applied for 30 seconds. Then, $500 \mathrm{~mL}$ of PBS ( $\mathrm{pH}$ 6.6) was used as the medium kept at $37^{\circ} \mathrm{C}$. Apparatus was run to allow the buccal tablet immersion into the medium at the lowest point. Time required for complete erosion or detachment from the tissue was recorded.

\section{Experimental design}

Mucoadhesive tablets of RIS were optimized by RSM. According to the results of polymer screening studies, CP (\%) and SA (\%) were selected as two numeric factors, and constraints were added to limit total polymer concentration between $30 \%$ and 50\%. I-optimal design with a quadratic model was employed, and 16 experiments were performed (Table 1). Critical response variables were determined as R1: tablet hardness (TH), R2: ex vivo RT, and R3: DF.

Table I Experimental design matrix and corresponding responses

\begin{tabular}{lllllll}
\hline Run & \multicolumn{2}{l}{ Variables } & & \multicolumn{2}{l}{ Responses } \\
\cline { 2 - 3 } \cline { 6 - 7 } & A (CP) & B (SA) & & RI (TH) & R2 (RT) & R3 (DF) \\
\hline 1 & 20 & 20 & 65.2 & 10 & 2.15 \\
2 & 25 & 15 & & 71.4 & 11 & 1.93 \\
3 & 20 & 20 & & 64.7 & 9.5 & 2.09 \\
4 & 10 & 40 & & 48.3 & 7 & 2.28 \\
5 & 20 & 10 & & 68.6 & 8.5 & 0.95 \\
6 & 30 & 20 & & 74.1 & 17 & 2.29 \\
7 & 20 & 30 & & 62.4 & 11 & 2.51 \\
8 & 25 & 15 & & 72.5 & 12 & 1.86 \\
9 & 13.3 & 16.7 & & 57.9 & 5.5 & 1.54 \\
10 & 30 & 10 & & 77.2 & 14 & 1.33 \\
11 & 10 & 26.7 & & 53.1 & 6 & 2.16 \\
12 & 40 & 10 & 81.4 & 22 & 1.62 \\
13 & 10 & 26.7 & & 52.9 & 6 & 2.07 \\
14 & 10 & 26.7 & 52.1 & 6.5 & 2.11 \\
15 & 25 & 25 & 67.0 & 14 & 2.55 \\
16 & 30 & 10 & 76.5 & 15 & 1.37 \\
$*$ & 16.4 & 20.3 & 46.2 & 8 & 1.99 \\
\hline
\end{tabular}

Note: *Optimized formulation with predicted responses.

Abbreviations: CP, carbopol (\%); DF, peak detachment force; RT, ex vivo residence time; SA, sodium alginate (\%); TH, tablet hardness.
DoEs and statistical analysis of the results were carried out using Design-Expert ${ }^{\circledR}$ software (Version. 10.0.5.0; Stat-Ease Inc., Minneapolis, MN, USA). Response was predicted by the following quadratic polynomial equation (Equation 4):

$$
\mathrm{Y}=\beta_{0}+\beta_{1} \mathrm{~A}+\beta_{2} \mathrm{~B}+\beta_{12} \mathrm{AB}+\beta_{11} \mathrm{~A}^{2}+\beta_{22} \mathrm{~B}^{2}
$$

where $\mathrm{Y}$ represents the predicted response, $\mathrm{A}$ and $\mathrm{B}$ indicate the independent variables, $\beta_{0}$ is the intercept value, $\beta_{1}$ and $\beta_{2}$ are linear coefficients of the model, $\beta_{12}$ is interaction coefficient, while $\beta_{11}$ and $\beta_{22}$ are quadratic coefficients. ${ }^{28,29}$

Analysis of variance (ANOVA) was employed to evaluate the effect of independent variables on the responses, and the results were considered statistically significant when $p$ was $<0.05$. Predicted and adjusted correlation coefficients $\left(\mathrm{R}^{2}\right)$ were calculated to evaluate the fitness of model. Experimental design region was visualized with three-dimensional (3D) surface graphs, and the effects of independent variables on the responses were observed. The optimized formulation was then prepared, and the obtained experimental results were compared with the predicted values.

\section{Fourier transform infrared (FT-IR) spectroscopy analysis}

FT-IR spectroscopy analysis was conducted to investigate any interaction between RIS, CP, SA, and other tablet excipients. ${ }^{30}$ For this purpose, IR spectra of the pure drug, polymers, and tablets were obtained in the range of 4,000-400 $\mathrm{cm}^{-1}$ with $4 \mathrm{~cm}^{-1}$ resolution by using an FT-IR spectrometer (Bruker Alpha ${ }^{\mathrm{TM}}$, Woodlands, TX, USA) equipped with OPUS 7.2 software. The system was operated in transmission mode.

\section{Differential scanning calorimetry (DSC) analysis}

DSC analysis was conducted on RIS, CP, SA, and buccal tablets by using a differential scanning calorimeter (DSC 4000; PerkinElmer, Waltham, MA, USA). Valuable information could thus be obtained to have an opinion on the crystal order of RIS and interactions between tablet ingredients. ${ }^{18}$ Briefly, $5 \mathrm{mg}$ of sample was weighed into the aluminum pan and heated from $100^{\circ} \mathrm{C}$ to $280^{\circ} \mathrm{C}$ with a heating rate of $20^{\circ} \mathrm{C} /$ min under $30 \mathrm{~mL} / \mathrm{min} \mathrm{N}_{2}$ flow. From the obtained thermograms, onset and melting points of the peaks were detected by the Pyris v11 software (Pelkin Elmer).

\section{Swelling and erosion analysis}

For the determination of swelling index (SI), tablets were weighed and fixed onto $2 \times 2 \mathrm{~cm}$ glass slides, which were then 
immersed in Petri dishes containing $10 \mathrm{~mL}$ of PBS (pH 6.6) medium. ${ }^{31}$ Temperature was kept constant at $37^{\circ} \mathrm{C} \pm 0.5^{\circ} \mathrm{C}$ during the study. After predetermined times, tablets were removed, and the excess surface water was wiped with filter papers. Swollen tablets were carefully reweighed, and SI was calculated by using Equation $5 .{ }^{30}$ Throughout the study, photographs of swollen tablets were also taken. Remaining tablets were kept at $60^{\circ} \mathrm{C}$ for 24 hours to completely remove excess water. They were reweighed until constant measurements were achieved, and matrix erosion (ME) was calculated by using Equation $6:{ }^{32}$

$$
\begin{gathered}
\mathrm{SI}(\%)=100 \frac{\left(\mathrm{W}_{\mathrm{t}}-\mathrm{W}_{0}\right)}{\mathrm{W}_{0}} \\
\operatorname{ME}(\%)=100 \frac{\left(\mathrm{W}_{0}-\mathrm{W}_{\mathrm{d}}\right)}{\mathrm{W}_{0}}
\end{gathered}
$$

where $\mathrm{W}_{\mathrm{t}}$ is the swollen tablet weight at a given time, $\mathrm{W}_{0}$ is the tablet weight obtained initially, and $\mathrm{W}_{\mathrm{d}}$ is the tablet weight after drying. All experiments were performed in triplicate.

\section{In vitro dissolution study}

Drug release studies were performed according to the USP 38 paddle method at $50 \mathrm{rpm}$ rotation speed by using a dissolution tester (Pharma Test PTWS 120D). ${ }^{23}$ Then, $500 \mathrm{~mL}$ of dissolution medium consisted of $0.5 \%(\mathrm{w} / \mathrm{v})$ sodium lauryl sulfate in PBS (pH 6.6) kept at $37^{\circ} \mathrm{C} \pm 0.5^{\circ} \mathrm{C}$ was used to ensure sink condition. At predetermined times, $0.5 \mathrm{~mL}$ of samples was taken, and an equal volume of fresh medium was supplied immediately to maintain a constant volume. Obtained samples were diluted suitably with mobile phase and analyzed utilizing HPLC. Pure drug was also subjected to dissolution as control. Drug release kinetics of buccal tablets were evaluated with zero-order, ${ }^{33}$ first-order, ${ }^{34}$ Hixson-Crowell, ${ }^{35}$ Higuchi, ${ }^{36}$ and Korsmeyer-Peppas ${ }^{37}$ mathematical equations.

\section{Results and discussion Polymer screening}

Sufficient powder flow is required for the transportation of powder mixtures to the funnel and, essentially, dye of the tableting machine during tablet production. Powders should be able to flow during this process without the need of additional vibration. According to the CI, HR, and AR values, flow characteristics and compressibility of powder mixtures were determined as shown in Table 2. Flow properties ranged from "good" to "passable" for all formulations, and the results indicated suitability of these formulations for direct compression process.

Tablet weights of all formulations were between $99.53 \pm 2.57 \mathrm{mg}$ and $100.91 \pm 1.12 \mathrm{mg}$, with RSDs $<5 \%$. Hardness of tablets differed significantly at fixed tablet thickness of $\sim 2 \mathrm{~mm}$ based on the polymer type and ranged from $32.57 \pm 3.54 \mathrm{~N}$ to $81.68 \pm 3.12 \mathrm{~N}$. TS calculated from the obtained hardness values varied between 1.27 and 3.71 , and it is an important parameter to determine the physical strength of buccal tablets. In general, TS value $>1.7 \mathrm{MPa}$ is desirable for large-scale manufacturing to ensure that the tablets possess sufficient mechanical properties. ${ }^{38}$ In this regard, $\mathrm{XG}, \mathrm{GG}$, and $\mathrm{SA}$ were not found suitable as sole polymers in this composition. FB results were found to be correlated with hardness values, and all tablet formulations (except $\mathrm{GG})$ were below the $1 \%$ upper acceptable limit. Lower FB is desirable for buccal tablets to retain physical shape and weight during packaging and transport. Ex vivo RT is an important parameter to ensure that buccal tablets retain on

\begin{tabular}{|c|c|c|c|c|c|c|c|c|c|c|}
\hline Polymer type & $\mathrm{Cl}(\%)$ & HR & $\operatorname{AR}\left({ }^{\circ}\right)$ & FC & WV (mg) & TH (N) & TS (MPa) & FB (\%) & RT (h) & DF (N) \\
\hline $\mathrm{CP}$ & 19.56 & 1.23 & $36.12 \pm 1.38$ & $F$ & $100.39 \pm 2.32$ & $81.68 \pm 3.12$ & 3.71 & 0.11 & 18 & $1.52 \pm 0.16$ \\
\hline HPMC & 20.29 & 1.25 & $40.83 \pm 1.46$ & $P$ & $100.88 \pm 2.90$ & $63.75 \pm 4.70$ & 2.89 & 0.22 & 10 & $1.16 \pm 0.14$ \\
\hline HEC & 15.85 & 1.18 & $36.90 \pm 1.09$ & $\mathrm{~F}$ & $99.53 \pm 2.57$ & $75.86 \pm 4.96$ & 3.45 & 0.36 & $<0.5$ & NA \\
\hline$X G$ & 14.86 & 1.17 & $35.61 \pm 1.12$ & G & $101.21 \pm 1.80$ & $32.57 \pm 3.54$ & 1.48 & 0.74 & 4 & $0.76 \pm 0.06$ \\
\hline GG & 13.80 & 1.16 & $34.68 \pm 1.14$ & G & $99.94 \pm|.5|$ & $27.94 \pm 2.55$ & 1.27 & 1.15 & $<0.5$ & $\mathrm{NA}$ \\
\hline AG & 22.82 & 1.30 & $40.69 \pm 1.75$ & $P$ & $100.34 \pm 2.57$ & $60.75 \pm 3.50$ & 2.76 & 0.23 & 2.5 & $0.61 \pm 0.07$ \\
\hline SA & $22.8 I$ & 1.30 & $41.20 \pm 2.10$ & $P$ & $99.71 \pm 1.94$ & $34.22 \pm 2.58$ & 1.56 & 0.51 & 4.5 & $2.05 \pm 0.16$ \\
\hline $\mathrm{CH}$ & 18.28 & 1.22 & $38.99 \pm 1.18$ & $F$ & $100.55 \pm 1.70$ & $37.48 \pm 3.06$ & 1.70 & 0.47 & 1.5 & $1.05 \pm 0.12$ \\
\hline PVP & 14.42 & 1.17 & $35.55 \pm 1.04$ & $\mathrm{~F}$ & $100.91 \pm 1.12$ & $50.51 \pm 3.19$ & 2.30 & 0.18 & I & $0.98 \pm 0.11$ \\
\hline * & 18.09 & 1.22 & $37.15 \pm 1.24$ & $\mathrm{~F}$ & $99.67 \pm 2.13$ & $45.52 \pm 3.85$ & 2.07 & 0.14 & 7.67 & $2.13 \pm 0.17$ \\
\hline
\end{tabular}

Table 2 Physical properties of powder mixtures and buccal tablets with different polymer types

Note: *Experimental parameters for optimized formulation.

Abbreviations: AG, acacia gum; AR, angle of repose; $\mathrm{CH}$, chitosan; $\mathrm{Cl}$, Carr's index; $\mathrm{CP}$, carbopol; DF, peak detachment force; $\mathrm{F}$, fair; FB, friability; FC, flow character; G, good; GG, guar gum; HEC, hydroxyethyl cellulose; HPMC, hydroxypropyl methylcellulose; HR, Hausner ratio; NA, not applicable; P, passable; PVP, polyvinylpyrrolidone; RT, ex vivo residence time; SA, sodium alginate; TH, tablet hardness; TS, tensile strength; $W V$, tablet weight variation; $X G$, xanthan gum. 
the buccal mucosa long enough to provide controlled drug delivery. CP tablets displayed 18-hour retention time, while HEC, GG, and PVP tablets undergone complete erosion within 1 hour. DF is also a critical parameter, and higher values are required to prevent the dislodgement of dosage form from the buccal mucosa during treatment. SA tablets displayed highest DF $(2.05 \pm 0.16 \mathrm{~N})$, while HEC and GG tablets began to disintegrate with contact to water and a reliable measurement could not be obtained.

As a result, tablets prepared with $\mathrm{CP}$ displayed the best mechanical properties, while SA tablets displayed the highest mucoadhesion. Therefore, further optimization studies were conducted with these two polymers.

\section{Experimental design}

\section{Design model}

Responses obtained from 16 experiments, and predicted values for optimized formulation are shown in Table 1. The following equations were used to determine the responses:

$$
\mathrm{R} 1=50.84-7.79 \mathrm{~A}-4.77 \mathrm{~B}-2.44 \mathrm{AB}-3.52 \mathrm{~A}^{2}-0.91 \mathrm{~B}^{2}
$$

$\mathrm{R} 2=13.78+10.15 \mathrm{~A}+2.54 \mathrm{~B}+0.9 \mathrm{AB}+2.15 \mathrm{~A}^{2}-0.32 \mathrm{~B}^{2}$

$$
\mathrm{R} 3=2.52+0.22 \mathrm{~A}+0.55 \mathrm{~B}-0.4 \mathrm{AB}-0.26 \mathrm{~A}^{2}-0.75 \mathrm{~B}^{2}
$$

where R1 is TH, R2 is ex vivo RT, R3 is DF from the buccal mucosa, while $\mathrm{A}$ and $\mathrm{B}$ are coded values for $\mathrm{CP}$ and $\mathrm{SA}$ $(\%, w / w)$. Regression models were analyzed by ANOVA as presented in Table 3 for R1, Table 4 for R2, and Table 5 for R3.

In the case of $\mathrm{R} 1$, high $\mathrm{F}$ value (536) and low $p$-value $(<0.0001)$ indicate that the model equation was statistically

Table 3 ANOVA results for response RI

\begin{tabular}{llllll}
\hline Source & $\begin{array}{l}\text { Sum of } \\
\text { squares }\end{array}$ & df & $\begin{array}{l}\text { Mean } \\
\text { square }\end{array}$ & F value & p-value \\
\hline Model & 869.30 & 5 & 173.86 & 536.00 & $<0.000$ I \\
A-A & $21.8 \mathrm{I}$ & $\mathrm{I}$ & $21.8 \mathrm{I}$ & 67.24 & $<0.000 \mathrm{I}$ \\
$\mathrm{B}-\mathrm{B}$ & 8.89 & $\mathrm{I}$ & 8.89 & 27.40 & 0.0004 \\
$\mathrm{AB}$ & 0.87 & $\mathrm{I}$ & 0.87 & 2.67 & 0.1332 \\
$\mathrm{~A} 2$ & 5.88 & $\mathrm{I}$ & 5.88 & 18.14 & 0.0017 \\
B2 & 0.44 & $\mathrm{I}$ & 0.44 & $\mathrm{I} .36$ & 0.2703 \\
Residual & 3.24 & $\mathrm{I} 0$ & 0.32 & & \\
Lack of fit & 2.37 & 5 & 0.47 & 2.73 & 0.1474 \\
Pure error & 0.87 & 5 & 0.17 & & \\
Total correlation & 872.54 & $\mathrm{I} 5$ & & & \\
\hline Note: & & &
\end{tabular}

Note: $R^{2}=0.9963$, adjusted $R^{2}=0.9944$, predicted $R^{2}=0.9875$.

Abbreviation: ANOVA, analysis of variance.
Table 4 ANOVA results for response R2

\begin{tabular}{llllll}
\hline Source & $\begin{array}{l}\text { Sum of } \\
\text { squares }\end{array}$ & df & $\begin{array}{l}\text { Mean } \\
\text { square }\end{array}$ & F value & p-value \\
\hline Model & 314.85 & 5 & 62.97 & 203.93 & $<0.0001$ \\
A-A & 36.88 & $\mathrm{I}$ & 36.88 & 119.43 & $<0.000 \mathrm{I}$ \\
B-B & 2.50 & $\mathrm{I}$ & 2.50 & $8.1 \mathrm{I}$ & 0.0173 \\
$\mathrm{AB}$ & 0.12 & $\mathrm{I}$ & 0.12 & 0.38 & 0.5500 \\
$\mathrm{~A} 2$ & 2.19 & $\mathrm{I}$ & 2.19 & 7.08 & 0.0239 \\
B2 & 0.056 & $\mathrm{I}$ & 0.056 & 0.18 & 0.6795 \\
Residual & 3.09 & $\mathrm{I} 0$ & $0.3 \mathrm{I}$ & & \\
Lack of fit & $\mathrm{I} .80$ & 5 & 0.36 & 1.39 & 0.3632 \\
Pure error & $\mathrm{I} .29$ & 5 & 0.26 & & \\
Total correlation & 317.94 & $\mathrm{I} 5$ & & & \\
\hline
\end{tabular}

Note: $R^{2}=0.9903$, adjusted $R^{2}=0.9854$, predicted $R^{2}=0.9594$.

Abbreviation: ANOVA, analysis of variance.

significant. On the other hand, statistically insignificant ( $p=0.1474$ ) lack of fit value indicates that the model fits well in this occasion. Confidence level of the regression model was verified by an $\mathrm{R}^{2}$ value of 0.9963 , which indicated that $99.63 \%$ of variability in the response can be explained by this model. Close agreement with the predicted $\mathrm{R}^{2}$ value of 0.9875 and the adjusted $\mathrm{R}^{2}$ value of 0.9944 demonstrated a high correlation between predicted and observed values. For $\mathrm{R} 2$, high model $\mathrm{F}$ value (203.93) and low $p$-value $(<0.0001)$ implied the significance of the model equation. Lack of fit of the model ( $p=0.363$ ) was not statistically significant. $\mathrm{R}^{2}$ value of 0.9903 indicated that $99.03 \%$ of variability in the response could be explained by the model. There was also a correlation between the adjusted $\mathrm{R}^{2}(=0.9854)$ and the predicted $\mathrm{R}^{2}(=0.9594)$, which indicated that the predictability of the model is high. As for R3, F value (146.77) was also high with a low $p$-value $(<0.0001)$, and statistically insignificant lack of fit $(p=0.097$ ) value demonstrating the model equation is significant and has a good fit. High $\mathrm{R}^{2}$ value (0.9866) of the model presented that $98.66 \%$ variability in

\begin{tabular}{|c|c|c|c|c|c|}
\hline Source & $\begin{array}{l}\text { Sum of } \\
\text { squares }\end{array}$ & df & $\begin{array}{l}\text { Mean } \\
\text { square }\end{array}$ & F value & $p$-value \\
\hline Model & 3.00 & 5 & 0.60 & | 46.77 & $<0.0001$ \\
\hline$A-A$ & 0.018 & I & 0.018 & 4.32 & 0.0644 \\
\hline B-B & 0.12 & I & 0.12 & 28.84 & 0.0003 \\
\hline$A B$ & 0.023 & I & 0.023 & 5.65 & 0.0388 \\
\hline $\mathrm{A} 2$ & 0.031 & I & 0.031 & 7.58 & 0.0204 \\
\hline B2 & 0.30 & 1 & 0.30 & 72.81 & $<0.0001$ \\
\hline Residual & $0.04 I$ & 10 & 0.0040 & & \\
\hline Lack of fit & 0.032 & 5 & 0.0063 & 3.48 & 0.0986 \\
\hline Pure error & 0.0091 & 5 & 0.0018 & & \\
\hline Total correlation & 3.04 & 15 & & & \\
\hline
\end{tabular}

Table 5 ANOVA results for response R3

Note: $R^{2}=0.9866$, adjusted $R^{2}=0.9798$, predicted $R^{2}=0.9140$.

Abbreviation: ANOVA, analysis of variance. 
the response can be explained, and there was a reasonable agreement between the adjusted $\mathrm{R}^{2}(=0.9798)$ and the predicted $\mathrm{R}^{2}(=0.9140)$ values.

\section{Formulation optimization}

Optimum formulation composition was determined from the obtained results of the design study. Design goals were set as maximized TH (R1), maximized DF (R3), and 8-hour ex vivo RT (R2). Figure 1A-C presents the 3D surface plots for R1, R2, and R3, respectively, as a function of CP and SA weight percentages.

In general, as $\mathrm{CP}$ concentration increased in the formulation, $\mathrm{TH}$ values were also increased as seen visually in Figure 1A. Steeper curve in Figure 1B indicates that there is a positive correlation with $\mathrm{CP}$ concentration and ex vivo $\mathrm{RT}$. On the other hand, an increase in SA concentration inside the formulation resulted in higher mucoadhesion as seen in Figure 1C. However, the combination of two polymers actually increased the mucoadhesion of the buccal tablets. Highly cross-linked structure of $\mathrm{CP}$ provides a large surface area for maximum contact with the mucosa. Carboxylic acid groups ionize in the presence of water and form hydrogen bonds with mucin glycoproteins. ${ }^{39}$ In case of SA, low surface tension and rapid swelling of polymer that result in good spreading may be the reason for synergistic effect in mucoadhesion strength. ${ }^{40}$

Coded variables for optimized formulation were found to be $A=16.4$ and $B=20.3$. Optimized formulation was prepared again in order to evaluate the model accuracy for the optimum conditions. RIS content in buccal tablets was found to be $98.23 \% \pm 2.12 \%$, which ensures uniform dosing. Table 2 summarizes the physical characterization studies for powder mixture and buccal tablet of the optimized formulation. Observed experimental values were in close
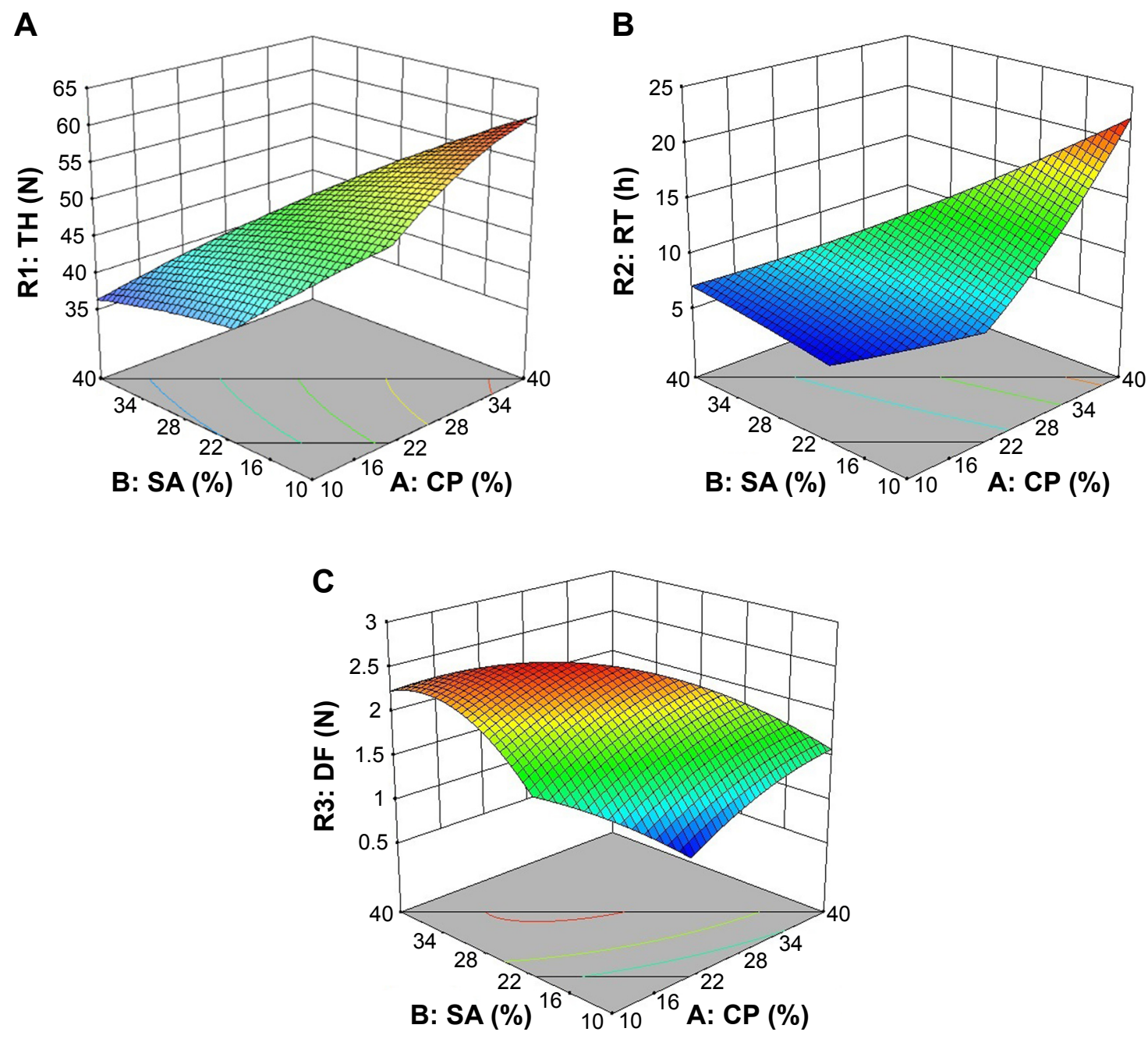

Figure I 3D response surface plots for (A) RI (TH), (B) R2 (RT), and (C) R3 (DF) as a function of SA and CP weight ratios (\%).

Abbreviations: 3D, three-dimensional; $\mathrm{CP}$, Carbopol; DF, peak detachment force (N); RT, ex vivo residence time (h); SA, sodium alginate; TH, tablet hardness (N). 
agreement $(\mathrm{RSD}<2 \%$ ) with the predicted values, indicating the significance and validity of the model.

\section{FT-IR spectroscopy analysis}

Figure 2 presents the results obtained from FT-IR spectroscopy analysis. The spectrum of RIS shows characteristic peaks of aromatic $\mathrm{C}-\mathrm{H}$ stretching band at $3,058 \mathrm{~cm}^{-1}$, strong $\mathrm{C}=\mathrm{O}$ stretching band at $1,644 \mathrm{~cm}^{-1}$, strong $\mathrm{N}-\mathrm{O}$ stretching band at $1,533 \mathrm{~cm}^{-1}, \mathrm{C}-\mathrm{N}$ stretching of the oxazole ring at $1,350 \mathrm{~cm}^{-1}$, strong $\mathrm{C}-\mathrm{F}$ stretching at $1,130 \mathrm{~cm}^{-1}$, and weak $\mathrm{C}-\mathrm{N}$ stretch of tertiary amine at piperidine ring at $1,192 \mathrm{~cm}^{-1}$. The spectrum of $\mathrm{CP}$ gives broad $-\mathrm{OH}$ stretching of carboxylic acid at $3,400-2,800 \mathrm{~cm}^{-1}, \mathrm{C}=\mathrm{O}$ stretching of carbonyl group at $1,699 \mathrm{~cm}^{-1}$, and $\mathrm{C}-\mathrm{OH}$ asymmetric stretching band at $1,166 \mathrm{~cm}^{-1}$. The spectrum of SA displays distinct peaks of $-\mathrm{OH}$ stretching centered around $3,200 \mathrm{~cm}^{-1}$, asymmetric and symmetric $-\mathrm{COO}-$ stretching at $1,613 \mathrm{~cm}^{-1}$ and $1,417 \mathrm{~cm}^{-1}$, respectively, and $\mathrm{C}-\mathrm{O}$ stretching at $1,025 \mathrm{~cm}^{-1}$.

Buccal tablet formulations displayed specific peaks of RIS, CP, and SA in FT-IR spectrum. However, significant reduction was observed in the peak intensities, possibly due to the existence of the other ingredients decreasing the concentrations. Decreases in the intensity of carbonyl groups were also evident, which may be attributed to the compression process, resulting in improved physical interactions such as the formation of hydrogen bonds. Thus, FT-IR analysis ruled out the existence of any incompatibility between LM, polymers, and RIS in buccal tablet formulation.

\section{DSC analysis}

Figure 3 displays the DSC thermograms of RIS, CP, SA, LM, and buccal tablet. Significant changes in the shape of the peaks and melting temperatures may indicate any interaction between drug and tablet ingredients. Chemical incompatibilities (hydrolysis, oxidation, or degradation) and solid-state incompatibilities (polymorphism or solubilization) can be detected by changes in the DSC thermograms of mixtures using pure RIS as a standard. Endothermic peak of RIS displayed a melting onset at $173.32^{\circ} \mathrm{C}$ and peak at $177.21^{\circ} \mathrm{C}$ with a melting enthalpy of $112.25 \mathrm{~J} / \mathrm{g}$. Melting temperature range of RIS does not overlap with the thermal profiles of other ingredients in the formulation. DSC profile of buccal tablet formulation displayed specific peaks of each ingredient at the corresponding temperature range. In case of RIS, melting onset and peak melting temperatures slightly decreased to $171.67^{\circ} \mathrm{C}$ and $175.94^{\circ} \mathrm{C}$, respectively. These small decreases may be caused by the existence of excipients at much higher concentration than that of RIS in the formulations. This phenomenon may also be attributed to drug crystals surrounded by polymer particles and lactose crystals getting in contact with RIS more closely during tablet compression. Moreover, compression might also cause breaking in crystal structures of tablet ingredients leading

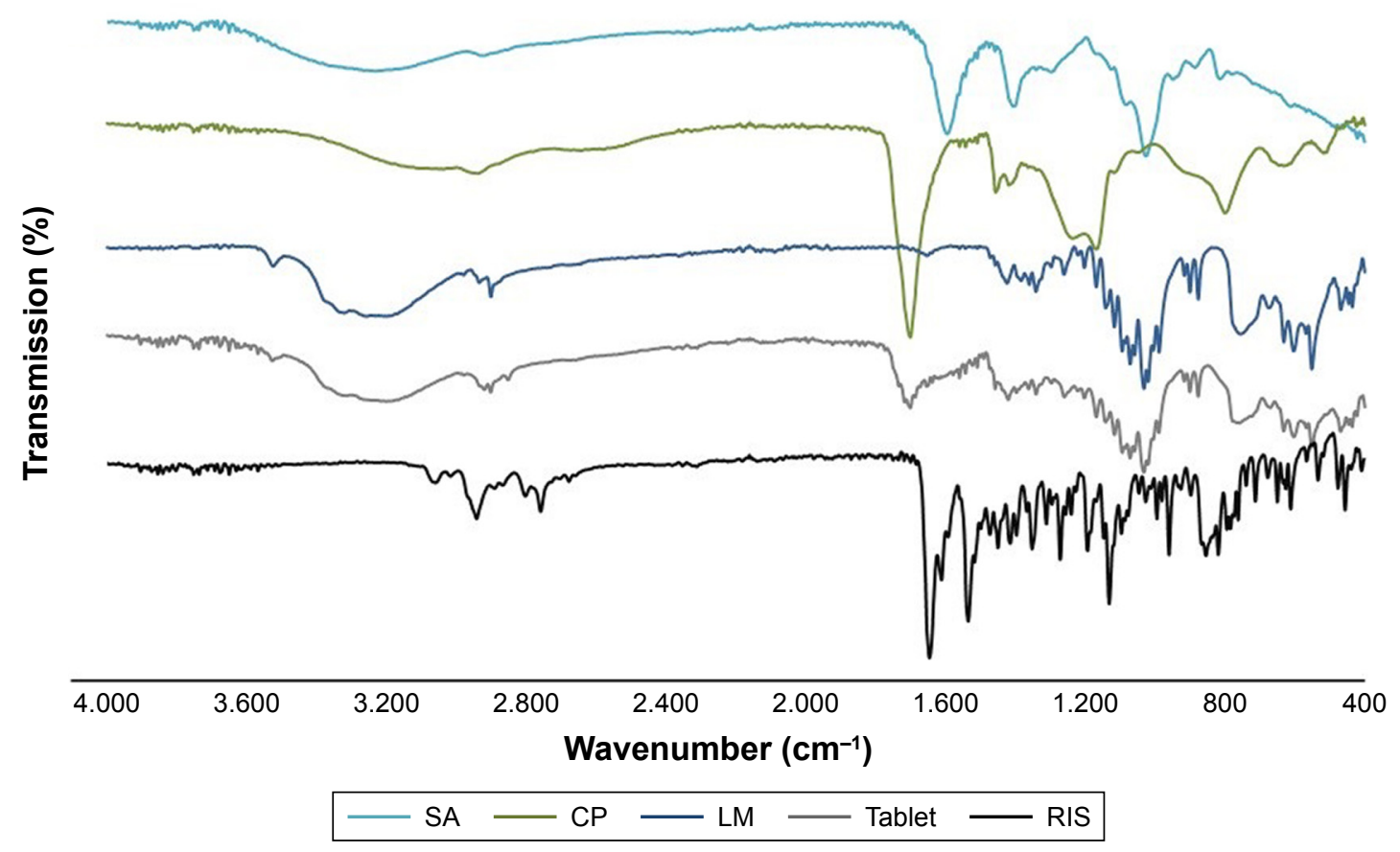

Figure 2 FT-IR spectra of RIS, CP, SA, LM, and buccal tablet.

Abbreviations: CP, carbopol; FT-IR, Fourier transform infrared; LM, lactose monohydrate; RIS, risperidone; SA, sodium alginate. 


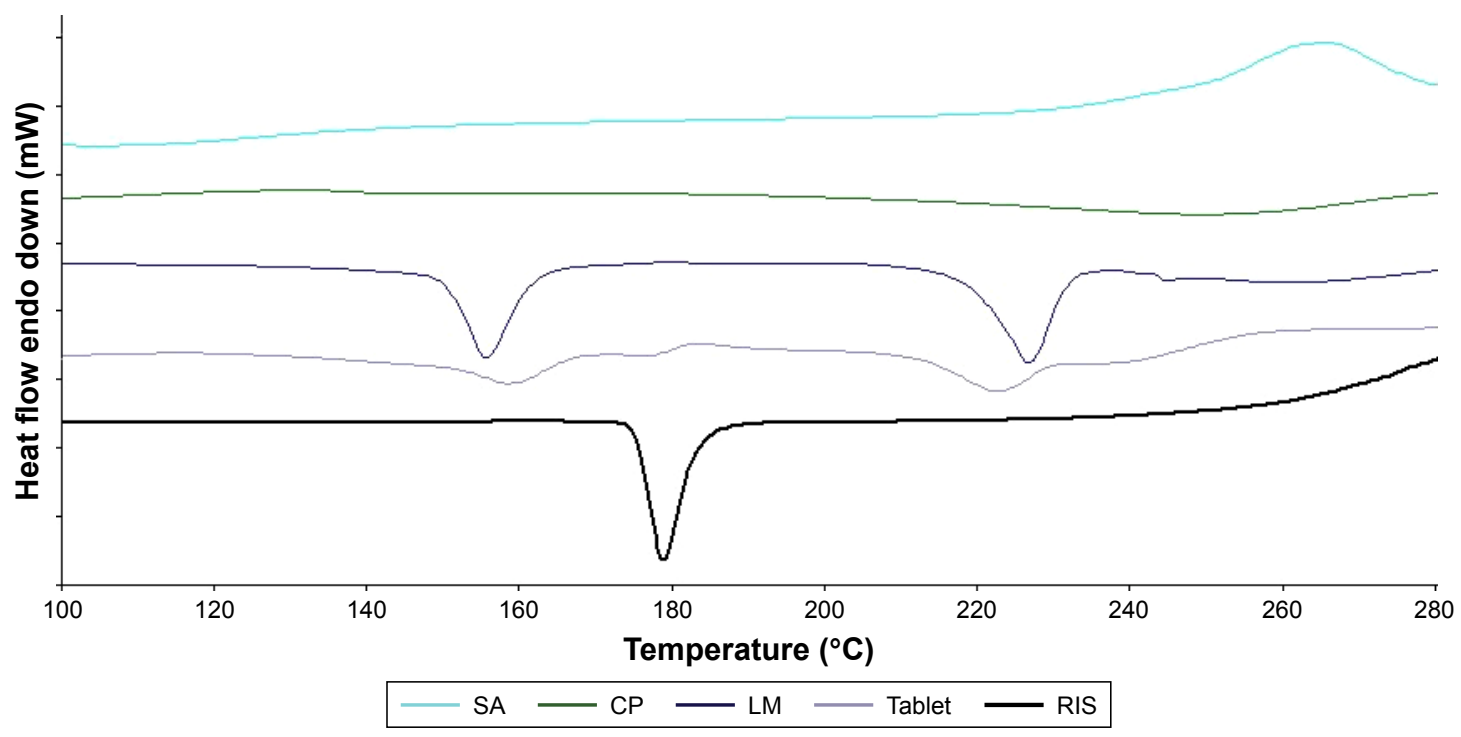

Figure 3 DSC thermograms of RIS, CP, SA, LM, and buccal tablet.

Abbreviations: CP, carbopol; DSC, differential scanning calorimetry; LM, lactose monohydrate; RIS, risperidone; SA, sodium alginate.

to a closer contact. As a result, DSC results were consistent with FT-IR spectroscopy results, which demonstrates the absence of chemical interactions, but the presence of physical interactions between drug and tablet excipients.

\section{Swelling and erosion analysis}

Appropriate swelling of a buccal tablet is an essential property for controlled and uniform drug release, required for drug absorption through buccal mucosa. Figure 4B and C presents the SI results and buccal tablet images taken during swelling studies. After contact with the medium, buccal tablets swelled rapidly peaking at 2 hours $(374.23 \% \pm 22.86 \%)$ and eroded gradually until 8 hours $(69.44 \% \pm 9.56 \%)$. ME studies revealed that the initial weight of $10.62 \% \pm 2.35 \%$ of buccal tablets remained after swelling studies. The results were in accordance with ex vivo RT results, which
A

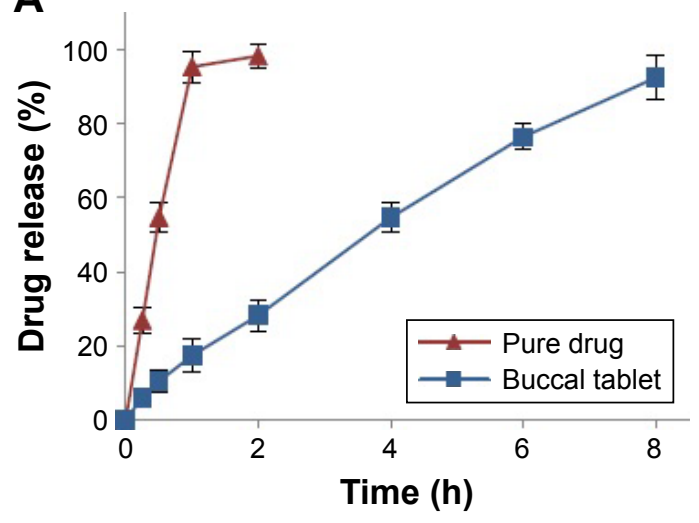

C
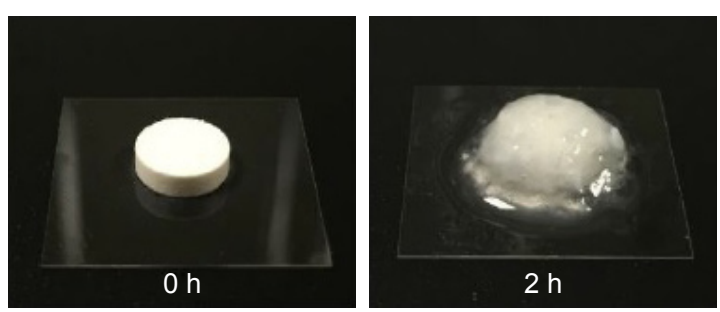

B
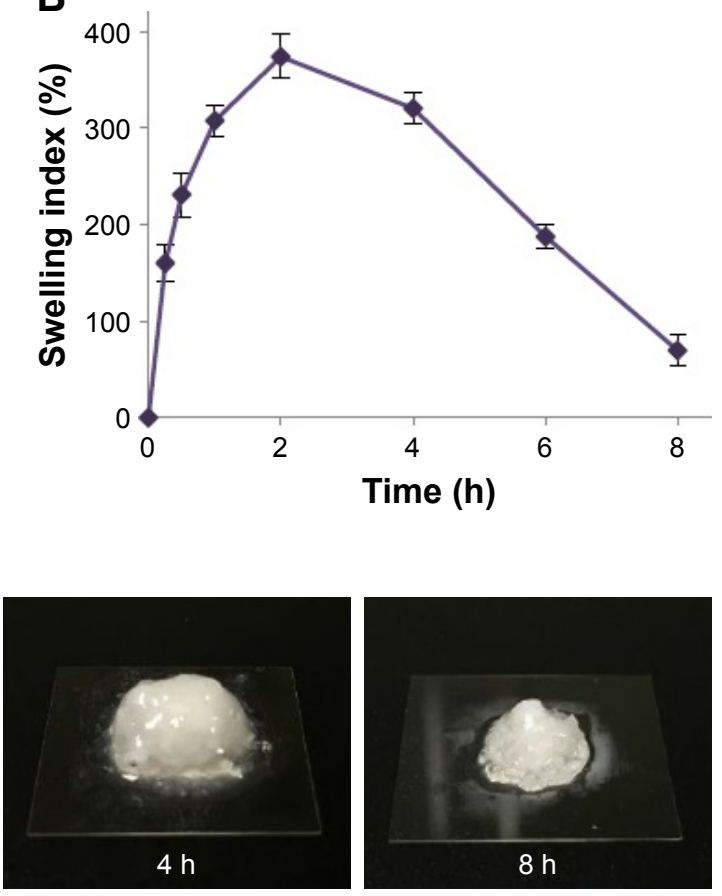

Figure 4 (A) In vitro release profile of RIS from buccal tablets. (B) Swelling index profile of buccal tablets. (C) Images of buccal tablets during swelling studies. Note: All data represent the mean \pm SD $(n=3)$. 
Table 6 In vitro release kinetics of RIS from optimized buccal tablets

\begin{tabular}{lll}
\hline Model & Kinetic constant & $\mathbf{R}^{\mathbf{2}}$ \\
\hline Zero-order & $\mathrm{II} .33\left(\mathrm{k}_{0}\right)$ & 0.9937 \\
First-order & $0.303\left(\mathrm{k}_{\mathrm{l}}\right)$ & 0.9503 \\
Higuchi & $37.80\left(\mathrm{k}_{\mathrm{H}}\right)$ & 0.9839 \\
Hixson-Crowell & $0.322\left(\mathrm{k}_{\mathrm{HC}}\right)$ & 0.9865 \\
Korsmeyer-Peppas & $0.77(\mathrm{n})$ & 0.9970 \\
Release-order & \multicolumn{2}{c}{ Anomalous (non-Fickian) } \\
\hline
\end{tabular}

Abbreviations: $\mathrm{k}_{0}$, zero-order release constant $(\mathrm{mg} \% / \mathrm{h})$; $\mathrm{k}_{1}$, first-order release constant $\left(\mathrm{h}^{-1}\right) ; \mathrm{k}_{\mathrm{H}}$, Higuchi release constant $\left(\mathrm{mg} \% / \mathrm{h}^{1 / 2}\right) ; \mathrm{k}_{\mathrm{HC}}$, Hixson-Crowell release constant $\left(\mathrm{mg} \% / \mathrm{h}^{1 / 2}\right) ; \mathrm{n}$, release exponent; $\mathrm{R}^{2}$, determination coefficient; RIS, risperidone.

displayed tablet detachment from the buccal mucosa after $7.67 \pm 0.29$ hours. CP is highly swellable in an aqueous environment above their $\mathrm{pKa}$ value of 6 , forming a gel layer around tablet formulation. ${ }^{41} \mathrm{Al}$-Zoubi et al also reported that an increase in SA concentration as opposed to CP in the formulation resulted in decreased swelling and increased erosion of matrix structure. ${ }^{42}$

\section{In vitro dissolution study}

Figure 4A shows the in vitro dissolution profiles of RIS and free drug as control. Cumulative RIS release of $10.48 \% \pm 3.05 \%$ was observed during the first 0.5 hour, indicating a slight burst release from buccal tablets. After that time, sustained drug release was observed until 8 hours reaching a cumulative release of $92.33 \% \pm 5.91 \%$. Buccal tablets maintained their shape and physical integrity throughout the study as also observed during SI studies.

In vitro release data were fitted to different models for the purpose of analyzing drug release mechanism. Table 6 presents the release kinetic constants $(\mathrm{k})$ and correlation coefficients $\left(\mathrm{R}^{2}\right)$ obtained for each model. Highest $\mathrm{R}^{2}$ values were obtained from zero-order kinetics, which describes a drug release mechanism independent from drug concentration. Fitting the first $60 \%$ of RIS release data to Korsmeyer-Peppas equation revealed that buccal tablets displayed non-Fickian (anomalous) kinetics $(0.45 \leq \mathrm{n}<0.89)$. After contact with dissolution medium, hydrophilic polymers swell rapidly and form a gel layer on buccal tablet surface. However, transfer of dissolution medium continues, and the gel layer outside the buccal tablet starts to regenerate, leading to tablet erosion over time. Drug release occurs by both diffusion through polymer matrices and the erosion of the polymer chain in this model. ${ }^{43}$

\section{Conclusion}

Controlled release buccal tablets of RIS were successfully designed and optimized with RSM studies for the first time using CP and SA as mucoadhesive polymers. Powder mixture of optimized formulation showed sufficient flow, and buccal tablets displayed sufficient physical properties and mucoadhesive characteristics. Design model was accurate as optimized formulation characteristics were in close agreement with predicted values. Buccal tablets displayed rapid swelling, and controlled drug release was achieved over 8 hours following zero-order release and non-Fickian (anomalous) kinetics. Overall, optimized formulation was proved to be suitable for large-scale production by direct compression.

It was concluded that buccal tablets designed and optimized for controlled delivery of RIS would be used as an alternative route of administration for the treatment of schizophrenia. Further clinical studies are required to determine pharmacokinetic properties, possible side effects, and in vivo performance of this formulation.

\section{Acknowledgment}

Special thanks to Dr Samet Özdemir from Department of Pharmaceutical Technology, Yeditepe University, for conducting DSC analysis.

\section{Disclosure}

The author reports no conflicts of interest in this work and is responsible for the content and writing of this paper.

\section{References}

1. Saibi Y, Sato H, Tachiki H. Developing in vitro-in vivo correlation of risperidone immediate release tablet. AAPS PharmSciTech. 2012; 13(3):890-895.

2. Rosenheck RA, Krystal JH, Lew R, et al. Long-Acting Risperidone and oral antipsychotics in unstable schizophrenia. $N$ Engl $\mathrm{J} \mathrm{Med.}$ 2011;364(9):842-851.

3. Kumar M, Misra A, Babbar AK, Mishra AK, Mishra P, Pathak K. Intranasal nanoemulsion based brain targeting drug delivery system of risperidone. Int J Pharm. 2008;358(1-2):285-291.

4. Weng W, Quan P, Liu C, Zhao H, Fang L. Design of a drug-in-adhesive transdermal patch for risperidone: effect of drug-additive interactions on the crystallization inhibition and in vitro/in vivo correlation study. J Pharm Sci. 2016;105(10):3153-3161.

5. Heemstra LB, Finnin BC, Nicolazzo JA. The buccal mucosa as an alternative route for the systemic delivery of risperidone. J Pharm Sci. 2010;99(11):4584-4592.

6. Pawar SV, Junagade MS. Formulation and evaluation of mouth dissolving film of risperidone. Int J PharmTech Res. 2015;8(6):218-230.

7. Manasa B, Gudas GK, Sravanthi N, Madhuri RA, Lavanya Y, Pranitha C. Formulation and evaluation of mucoadhesive buccal patches of risperidone. J Chem Pharm Res. 2010;2(4):866-872.

8. Smart JD. Buccal drug delivery. Expert Opin Drug Deliv. 2005;2(3): 507-517.

9. Madhav NV, Shakya AK, Shakya P, Singh K. Orotransmucosal drug delivery systems: a review. J Control Release. 2009;140(1):2-11.

10. Gilhotra RM, Ikram M, Srivastava S, Gilhotra N. A clinical perspective on mucoadhesive buccal drug delivery systems. J Biomed Res. 2014; 28(2):81-97. 
11. Boyapally H, Nukala RK, Bhujbal P, Douroumis D. Controlled release from directly compressible theophylline buccal tablets. Colloids Surf B Biointerfaces. 2010;77(2):227-233.

12. Gajdziok J, Bajerová M, Chalupová Z, Rabišková M. Oxycellulose as mucoadhesive polymer in buccal tablets. Drug Dev Ind Pharm. 2010; 36(9):1115-1130.

13. Abruzzo A, Cerchiara T, Bigucci F, Gallucci MC, Luppi B. Mucoadhesive buccal tablets based on chitosan/gelatin microparticles for delivery of propranolol hydrochloride. J Pharm Sci. 2015;104(12):4365-4372.

14. Laffleur F. Mucoadhesive polymers for buccal drug delivery. Drug Dev Ind Pharm. 2014;40(5):591-598.

15. Smart JD. The basics and underlying mechanisms of mucoadhesion. Adv Drug Deliv Rev. 2005;57(11):1556-1568.

16. El-Nabarawi MA, Ali AA, Aboud HM, Hassan AH, Godah AH. Transbuccal delivery of betahistine dihydrochloride from mucoadhesive tablets with a unidirectional drug flow: in vitro, ex vivo and in vivo evaluation. Drug Des Devel Ther. 2016;10:4031-4045.

17. Yu LX. Pharmaceutical quality by design: product and process development, understanding, and control. Pharm Res. 2008;25(4):781-791.

18. Mylangam CK, Beeravelli S, Medikonda J, Pidaparthi JS, Kolapalli VRM. Badam gum: a natural polymer in mucoadhesive drug delivery. Design, optimization, and biopharmaceutical evaluation of badam gum-based metoprolol succinate buccoadhesive tablets. Drug Deliv. 2016;23(1) 195-206.

19. Madgulkar AR, Bhalekar MR, Kolhe VJ, Kenjale YD. Formulation and optimization of sustained release tablets of venlafaxine resinates using response surface methodology. Indian J Pharm Sci. 2009;71(4): 387-394.

20. Çelik B, Özdemir S, Barla Demirkoz A, Üner M. Optimization of piribedil mucoadhesive tablets for efficient therapy of Parkinson's disease: physical characterization and ex vivo drug permeation through buccal mucosa. Drug Dev Ind Pharm. 2017;43(11):1836-1845.

21. Carr RL. Evaluating flow properties of solids. Chem Eng. 1965;72: 163-168.

22. Hausner HH. Friction conditions in a mass of metal powder. Int $J$ Powder Metall. 1967;3:7-13.

23. USP 38 NF 33: United States Pharmacopeia and National Formulary. Rockville, MD: United States Pharmacopeial Convention; 2015.

24. Dedania ZR, Dedania RR, Sheth NR, Patel JB, Patel B. Stability indicating HPLC determination of risperidone in bulk drug and pharmaceutical formulations. Int J Anal Chem. 2011;2011:6.

25. Baldania SL, Bhatt KK, Mehta RS, Shah DA. RP-HPLC estimation of risperidone in tablet dosage forms. Indian J Pharm Sci. 2008;70(4): 494-497

26. Jaipal A, Pandey MM, Charde SY, Sadhu N, Srinivas A, Prasad RG. Controlled release effervescent buccal discs of buspirone hydrochloride: in vitro and in vivo evaluation studies. Drug Deliv. 2016;23(2): 452-458.

27. Madgulkar A, Kadam S, Pokharkar V. Development of buccal adhesive tablet with prolonged antifungal activity: optimization and ex vivo deposition studies. Indian J Pharm Sci. 2009;71(3):290-294.
28. Ravar F, Saadat E, Kelishadi PD, Dorkoosh FA. Liposomal formulation for co-delivery of paclitaxel and lapatinib, preparation, characterization and optimization. J Liposome Res. 2016;26(3):175-187.

29. Çelik B, Sağıroğlu AA, Özdemir S. Design, optimization and characterization of coenzyme Q10- and D-panthenyl triacetate-loaded liposomes. Int J Nanomedicine. 2017;12:4869-4878.

30. Sogias IA, Williams AC, Khutoryanskiy VV. Chitosan-based mucoadhesive tablets for oral delivery of ibuprofen. Int J Pharm. 2012; 436(1-2):602-610.

31. Shanker G, Kumar CK, Gonugunta CS, Kumar BV, Veerareddy PR. Formulation and evaluation of bioadhesive buccal drug delivery of tizanidine hydrochloride tablets. AAPS PharmSciTech. 2009;10(2): 530-539.

32. SriamornsakP, Thirawong N, Weerapol Y, Nunthanid J, Sungthongjeen S. Swelling and erosion of pectin matrix tablets and their impact on drug release behavior. Eur J Pharm Biopharm. 2007;67(1):211-219.

33. Varelas CG, Dixon DG, Steiner CA. Zero-order release from biphasic polymer hydrogels. J Control Release . 1995;34(3):185-192.

34. Wagner JG. Interpretation of percent dissolved-time plots derived from in vitro testing of conventional tablets and capsules. J Pharm Sci. 1969;58(10):1253-1257.

35. Hixson AW, Crowell JH. Dependence of reaction velocity upon surface and agitation. Ind Eng Chem. 1931;23(8):923-931.

36. Higuchi T. Rate of release of medicaments from ointment bases containing drugs in suspension. J Pharm Sci. 1961;50(10):874-875.

37. Korsmeyer RW, Gurny R, Doelker E, Buri PA, Peppas NA. Mechanisms of solute release from porous hydrophilic polymers. Int J Pharm. 1983;15(1):25-35.

38. Pitt KG, Heasley MG. Determination of the tensile strength of elongated tablets. Powder Technol. 2013;238:169-175.

39. Nafee NA, Ismail FA, Boraie NA, Mortada LM. Mucoadhesive delivery systems. I. Evaluation of mucoadhesive polymers for buccal tablet formulation. Drug Dev Ind Pharm. 2004;30(9):985-993.

40. Kesavan K, Nath G, Pandit JK. Sodium alginate based mucoadhesive system for gatifloxacin and its in vitro antibacterial activity. Sci Pharm. 2010;78(4):941-957.

41. Obeidat WM, Nokhodchi A, Alkhatib H. Evaluation of matrix tablets based on Eudragit ${ }^{\circledR} \mathrm{E} 100 / \mathrm{Carbopo}^{\circledR} 971 \mathrm{P}$ combinations for controlled release and improved compaction properties of water soluble model drug paracetamol. AAPS PharmSciTech. 2015;16(5):1169-1179.

42. Al-Zoubi NM, AlKhatib HS, Obeidat WM. Evaluation of hydrophilic matrix tablets based on Carbopol ${ }^{\circledR}$ 971P and low-viscosity sodium alginate for $\mathrm{pH}$-independent controlled drug release. Drug Dev Ind Pharm. 2011;37(7):798-808.

43. Abdelkader H, Abdalla OY, Salem H. Formulation of controlledrelease baclofen matrix tablets: Influence of some hydrophilic polymers on the release rate and in vitro evaluation. AAPS PharmSciTech. 2007;8(4):E100
Drug Design, Development and Therapy

\section{Publish your work in this journal}

Drug Design, Development and Therapy is an international, peerreviewed open-access journal that spans the spectrum of drug design and development through to clinical applications. Clinical outcomes, patient safety, and programs for the development and effective, safe, and sustained use of medicines are the features of the journal, which

\section{Dovepress}

has also been accepted for indexing on PubMed Central. The manuscript management system is completely online and includes a very quick and fair peer-review system, which is all easy to use. Visit http://www.dovepress.com/testimonials.php to read real quotes from published authors. 